\title{
PENERAPAN SISTEM AKUNTABILITAS KINERJA INSTANSI PEMERINTAH (SAKIP) PADA PEMERINTAH KABUPATEN GUNUNGKIDUL
}

\author{
APPLICATION OF ACCOUNTABILITY PERFORMANCE OF \\ GOVERNMENT INSTITUTIONS (SAKIP) IN GUNUNGKIDUL \\ GOVERNMENT
}

Muh. Irfandy Azis

Universitas Borneo Tarakan

Email: muh.irfandyazis@gmail.com

\begin{abstract}
Abstrak : Penelitian ini adalah penelitian kualitatif dengan pendekatan studi kasus. Tujuan penelitian ini adalah untuk mengevaluasi SAKIP pada Pemerintah Kabupaten Gunungkidul yang memperoleh nilai SAKIP yang tetap. Metode analisis deskriptif digunakan untuk mengevaluasi komponen SAKIP yaitu Perencanaan Kinerja, Pengukuran Kinerja, Pelaporan Kinerja, Evaluasi Kinerja dan Capaian Kinerja. Hasil penelitian terhadap evaluasi SAKIP Kabupaten Gunungkidul menunjukkan bahwa faktor yang mempengaruhi SAKIP Kabupaten Gunungkidul adalah kejelasan pedoman SAKIP, komitmen Pemerintah Daerah dan bantuan pemerintah pusat. Sedangkan kendala yang dihadapi Kabupaten Gunungkidul adalah kurangnya pemahaman tentang pedoman SAKIP, kurangnya komitmen Pemerintah Daerah yang ditandai dengan anggaran SAKIP yang kecil sehingga membuat penerapan SAKIP Kabupaten Gunungkidul kurang optimal.
\end{abstract}

Kata kunci: Akuntabilitas, Kinerja, SAKIP

Abstract: This research is a qualitative case study approach. The purpose of this study was to evaluation results SAKIP of Gunungkidul Regency which has grades SAKIP fixed over 5 years. Descriptive analysis method is used to evaluation components SAKIP namely Performance Planning, Performance Measurement, Performance Reporting, Performance Evaluation and Performance Achievement. The results showed that the evaluation SAKIP of Gunungkidul Regency is factors that effect SAKIP of Gunungkidul Regency are the clarity of SAKIP guidelines, commitment of the Regional Government, and central government assistance. There are obstacles related to the lack of understanding of SAKIP guidelines, then the lack of commitment by the Regional Government marked by a small budget of SAKIP makes the application of SAKIP of Gunungkidul Regency less than optimal.

Keywords: Accountability, Performance, SAKIP 


\section{PENDAHULUAN}

Berdasarkan Inpres No. 7 Tahun 1999 tentang akuntabilitas instansi pemerintah, setiap instansi pemerintah wajib

mempertanggungjawabkan

penyelenggaran

pemerintahan dengan membuat laporan akuntabilitas kinerja instansi pemerintah. Sedangkan menurut Peraturan Presiden No. 29 Tahun 2014 Tentang Sistem Akuntabilitas Kinerja Instansi Pemerintah, Sistem Akuntabilitas Kinerja Instansi Pemerintah (SAKIP) merupakan integrasi dari berbagai aktivitas mulai dari sistem pengumpulan data, sistem pengukuran dan sistem pelaporan kinerja untuk mempertanggungjawabkan penyelenggaraan pemerintahan dan untuk meningkatkan kinerja instansi pemerintah.

Penerapan

Sistem Akuntabilitas dan Kinerja Instansi Pemerintah (SAKIP) dapat berperan dalam mengukur dan meningkatkan kinerja pemerintah, selain itu penerapan SAKIP juga berdampak pada penyusunan anggaran yang berdasarkan kinerja. Pemerintah Kabupaten Gunungkidul telah melaksanakan Sistem Akuntabilitas Kinerja dan Instansi Pemerintah selama lima tahun terakhir. Hasil evaluasi SAKIP yang dilakukan oleh Kementerian Negara Pendayagunaan Aparatur Negara dan Reformasi Birokrasi (Kemen PAN \& RB) pada Pemerintah Kabupaten Gunungkidul adalah sebagai berikut:
Tabel 1

\section{Hasil Evaluasi SAKIP Kabupaten Gunungkidul Tahun 2011-2015}

\begin{tabular}{c|c|c}
\hline Tahun & Nilai & Kategori \\
\hline 2011 & CC & Cukup Baik/Memadai \\
\hline 2012 & CC & Cukup Baik/Memadai \\
\hline 2013 & CC & Cukup Baik/Memadai \\
\hline 2014 & CC & Cukup Baik/Memadai \\
\hline 2015 & CC & Cukup Baik/Memadai \\
\hline
\end{tabular}

Berdasarkan tabel 1 di atas, hasil evaluasi SAKIP terhadap Kabupaten Kabupaten Gunungkidul yang selama tahun 2011-2015 masih memperoleh predikat "CC" (cukup baik/memadai). Hasil evaluasi SAKIP pada Kabupaten Gunungkidul yang konstan selama tahun 2011-2015 ditengarai disebabkan karena adanya masalah pada penerapan SAKIP mulai dari aspek perencanaan, pengukuran kinerja, pelaporan kinerja, evaluasi kinerja, dan capaian kinerja. Oleh karena itu, perlu dilakukan penelitian yang berjudul "Evaluasi Sistem Akuntabilitas Kinerja Instansi Pemerintah pada Kabupaten Gunungkidul".

\section{TINJAUAN PUSTAKA}

Perencanaan Strategi Instansi Pemerintah

Berdasarkan Keputusan Kepala Lembaga Administrasi Negara No. 239/IX/6/8/2003 tentang Perbaikan Pedoman Penyusunan Pelaporan Akuntabilitas Kinerja Instansi Pemerintah, tahap awal yang harus dilakukan oleh setiap instansi pemerintah untuk menjawab tuntutan lingkungan strategi dalam lingkup lokal, lingkup nasional dan lingkup 
global adalah perencanaan strategi. Dokumen perencanaan strategis mencakup periode 5 tahunan. Perencanaan strategi dilakukan dengan tidak terlepas dalam tatanan Sistem Administrasi Negara Kesatuan Republik Indonesia.

Perencanaan Kinerja Instansi $\underline{\text { Pemerintah }}$

Tahap selanjutnya setelah menyusunan perencanaan strategi adalah perencanaan kinerja. Berdasarkan Peraturan Pemerintah No 8 Tahun 2008 tentang Tahapan, Tata Cara Penyusunan, Pengendalian dan Evaluasi Pelaksanaan Rencana Pembangunan Daerah, perencanaan kinerja dilakukan dengan menyusun dokumen yang mencakup periode satu tahunan proses penjabaran lebih lanjut dari sasaran dan program yang telah ditetapkan dalam rencana strategi (renstra). Dokumen perencanaan kinerja mencakup periode satu tahunan.

Perjanjian Kinerja Instansi $\underline{\text { Pemerintah }}$

Setelah dokumen perencanaan kinerja disusun oleh instansi pemerintah, dokumen selanjutnya yang harus disiapkan adalah perjanjian kinerja. Berdasarkan Peraturan Presiden No 29 Tahun 2014 tentang Sistem Akuntabilitas Kinerja Instansi Pemerintah (SAKIP), perjanjian kinerja merupakan suatu bentuk perintah dari pimpinan instansi pemerintah yang lebih tinggi kepada pimpinan instansi pemerintah yang lebih rendah atau bawahan untuk melaksanakan program atau kegiatan yang dituangkan didalam sebuah dokumen. Perjanjian kinerja juga mencakup indikator kinerja dari setiap program atau kegiatan. Sama halnya dengan dokumen perencanaan kinerja, dokumen perjanjian kinerja mencakup periode satu tahunan.

\section{Pengukuran Kinerja}

Setelah dokumen dari sistem perencanaan yaitu perencanaan strategis, perencanaan kinerja dan perjanjian kinerja disusun, instansi pemerintah melaksanakan setiap program dan kegiatan yang tertuang dalam dokumen tersebut. Untuk mengetahui kinerja yang telah dicapai maka perlu dilakukan suatu proses pengukuran kinerja instansi pemerintah. Berdasarkan Keputusan Lembaga Administrasi Negara No:239/IX/6/8/2003 tentang Perbaikan Pedoman Penyusunan Pelaporan Akuntabilitas Kinerja Instansi Pemerintah, Pengukuran kinerja bertujuan untuk menilai keberhasilan dan kegagalan pelaksanaan kegiatan sesuai dengan yang telah ditetapkan dalam dokumen perencanaan.

Laporan Akuntabilitas Kinerja $\underline{\text { Instansi Pemerintah (LAKIP) }}$

Untuk melaporkan hasil pengukuran kinerja maka dibutuhkan suatu dokumen laporan kinerja. Pada instansi pemerintah laporan kinerja yang disusun adalah Laporan Akuntabilitas Kinerja Instansi Pemerintah (LAKIP). Berdasarkan Keputusan Lembaga Administrasi Negara No:239/IX/6/8/2003 tentang Perbaikan Pedoman Penyusunan Pelaporan Akuntabilitas Kinerja Instansi Pemerintah, LAKIP dapat 
bermanfaat dalam mewujudkan pemerintahan yang baik, bersih dan produktivitas. LAKIP harus disampaikan secara periodik dan disampaikan selambat-lambatnya 3 (tiga) bulan setelah tahun anggaran berakhir.

\section{$\underline{\text { Evaluasi Kinerja }}$}

Keputusan

Administrasi

No:239/IX/6/8/2003

Lembaga Negara tentang

Perbaikan Pedoman Penyusunan Pelaporan Akuntabilitas Kinerja Instansi Pemerintah, menyatakan bahwa evaluasi kinerja dilakukan dengan memberikan penjelasan tentang faktor-faktor yang mendukung keberhasilan dan kegagalan pada pencapaian kinerja yang ada dalam dokumen pengukuran kinerja.

\section{METODOLOGI PENELITIAN}

\section{Desain Penelitian}

Penelitian ini merupakan jenis penelitian kualitatif. Mengamati dan mempelajari secara langsung adalah aktivitas yang akan dilakukan peneliti dalam memberikan rekomendari pemecahan masalah berkaitan dengan penerapan Sistem Akuntabilitas dan Kinerja Instansi Pemerintah (SAKIP) pada Pemerintah Kabupaten Gunungkidul.

\section{$\underline{\text { Sumber Data }}$}

Sumber data yang digunakan dalam penelitian ini adalah data primer yang diperoleh dari hasil wawancara oleh beberapa narasumber dan data sekunder yang diperoleh dari dokumentasi dari dokumen yang berkaitan dengan SAKIP.

\section{$\underline{\text { Keabsahan Data }}$}

Teknik keabsahan data (muthoharoh, 2009) yang digunakan adalah triangulasi dan membercheck. Triangulasi merupakan teknik untuk memeriksa keabsahan data dengan melakukan pengecakan dan pembandingan pada data yang ada di luar penelitian, sedangkan teknik memberchek merupakan teknik untuk memeriksa keabsahan data dengan mendatangi kembali narasumber dengan memperlihat paparan data dan hasil penelitian yang sebelumnya sudah diketik pada sebuah dokumen.

$\underline{\text { Teknik Analisis Data }}$

Penelitian ini menggunakan teknik analisis model interaktif melalui Reduksi Data, interpretasi data, penyajian data dan penarikan kesimpulan.

\section{HASIL DAN PEMBAHASAN}

Berdasarkan hasil wawancara dan dokumentasi pada dokumen Sistem Akuntabilitas dan Kinerja Instansi Pemerintah (SAKIP), maka penerapan SAKIP pada Pemerintah Daerah Kabupaten Gunungkidul terbagi menjadi perencanaan kinerja, pengukuran kinerja, pelaporan kinerja, evaluasi kinerja dan capaian kinerja.

\section{Perencanaan Kinerja}

Berdasarkan hasil wawancara dan dokumentasi terhadap RPJMD, 
RKT dan Perjanjian Kinerja diperoleh informasi bahwa sasaran dan indikator kinerja daerah masih banyak yang belum berorientasi outcome atau masih berorientasi output. Selain itu, Pemerintah Kabupaten Gunungkidul telah melaksanakan review RPJMD Tahun 2010-2015 selama satu kali pada Tahun 2013 yang ditandai dengan adanya perubahan RPJMD Pemerintah Kabupaten Gunungkidul. Indikator-indikator kinerja sasaran yang ada dalam dokumen RKT atau dalam hal ini adalah Indikator Kinerja Utama (IKU) Pemerintah Kabupaten Gunungkidul masih banyak yang belum berorientasi outcome atau masih berorientasi output.

\section{$\underline{\text { Pengukuran Kinerja }}$}

Berdasarkan hasil wawancara dan dokumentasi, Indikator Kinerja Utama (IKU) Pemerintah Kabupaten Gunungkidul masih memiliki masalah terkait banyaknya indikator yang berorientasi output. Review IKU dilaksanakan Pemerintah Kabupaten Gunungkidul dengan melakukan review RPJMD yang dilaksanakan oleh BAPPEDA setiap satu tahun sekali.

Pemerintah Daerah Kabupaten Gunungkidul belum menerapkan sistem pengumpulan data kinerja yang terintegrasi. Pengumpulan data kinerja yang dilaksanakan oleh Pemerintah Kabupaten Gunungkidul masih secara manual dengan meminta langsung data kinerja pada SKPD-SKPD penanggungjawab. Akan tetapi, Pemerintah Kabupaten Gunungkidul berusaha untuk menerapkan sistem pengumpulan data kinerja yang efektif dan efisien dengan berusaha membuat sistem eSAKIP melalui pemberdayaan PNS internal Pemerintah Daerah.

Selain itu pengumpulan data kinerja Pemerintah Kabupaten Gunungkidul belum dilaksanakan secara berkala (bulanan, triwulanan dan semesteran), pengumpulan data kinerja Pemerintah Kabupaten Gunungkidul dilaksanakan dalam periode satu tahun sekali.

\section{Pelaporan Kinerja}

Berdasarkan hasil wawancara dan dokumentasi, Jumlah anggaran untuk penyusunan laporan Akuntabilitas dan Kinerja Instansi Pemerintah (LAKIP) pada Pemerintah Kabupaten Gunungkidul adalah sebesar Rp. 38.130.000. Anggaran tersebut digunakan untuk biaya pembuatan dokumen LAKIP, biaya sosialisasi, biaya bimtek termasuk didalamnya biaya pembuatan e-SAKIP dari pemberdayaan PNS daerah.

$$
\text { Pada dokumen LAKIP, }
$$

Pemerintah Kabupaten Gunungkidul tidak melampirkan hasil review LAKIP. Selain itu, pada dokumen LAKIP Pemerintah Kabupaten Gunungkidul tidak menampilkan informasi penghargaan-penghargaan yang diterima daerah selama satu tahun.

\section{$\underline{\text { Evaluasi Kinerja }}$}

Berdasarkan hasil wawancara dan dokumentasi, Pemerintah Daerah Kabupaten Gunungkidul melaksanakan evaluasi yang dilakukan oleh Inspektorat Daerah. Sedangkan analisis capaian kinerja 
dilakukan oleh tim yang dibentuk oleh Pemerintah Daerah Kabupaten Gunungkidul dengan memperhatikan faktor-faktor yang mempengaruhi keberhasilan pencapaian sasaran strategis serta hambatan/masalah dan strategi pemecahan masalah.

Sedangkan analisis terhadap faktor-faktor keberhasilan maupun hambatan dalam pelaksanaan sasaran strategis dan Indikator Kinerja Utama, dilaksanakan oleh SKPD penaggungjawab dan tim yang disusun oleh masing-masing Pemerintah Daerah.

\section{$\underline{\text { Capaian Kinerja }}$}

Berdasarkan hasil wawancara dan dokumentasi, capaian sasaran Pemerintah Daerah Kabupaten Gunungkidul berdasarkan indikator yang ditetapkan, sebagian besar telah terpenuhi sesuai dengan target yang ditetapkan. Dari 23 (dua puluh tiga) sasaran yang ditetapkan dapat tercapai dengan kategori sangat berhasil.

Pemerintah Daerah Kabupaten Gunungkidul tidak mencantumkan penjelasan mengenai penghargaan level nasional yang telah diterima. Selain itu, Pemerintah Daerah Kabupaten Gunungkidul masih memiliki kendala terkait indikatorindikator kinerja yang masih orientasi output.

\section{$\underline{\text { Diskusi }}$}

Berdasarkan hasil wawancara, kurang optimalnya penerapan SAKIP pada Pemerintah Kabupaten Gunungkidul disebabkan oleh beberapa hal yaitu sebagai berikut:
1. Kurangnya pemahaman Pemerintah Daerah Kabupaten Gunungkidul tentang indikator yang baik atau indikator outcome. Selain itu, Pemerintah Kabupaten Gunungkidul juga mengalami masalah pemahaman kebijakan atau peraturan terkait penerapan SAKIP khususnya dalam penentuan indikator kinerja. Banyaknya peraturan yang mengatur terkait penentuan indikator kinerja tersebut, mulai dari peraturan dari Kementerian Dalam Negeri dan Kementerian PAN \& RB dianggap sebagai peraturan yang tumpang-tindih oleh Pemerintah Kabupaten Gunungkidul. Pengikutsertaan pihak ketiga atau dalam hal ini pihak dari akademisi atau pihak dari Pemerintah Pusat yang belum dilaksanakan oleh Pemerintah Kabupaten Gunungkidul, diakibatkan belum adanya anggaran dalam perencanaan tersebut. Akan tetapi, pada tahun 2016 Pemerintah Kabupaten Gunungkidul sudah berencana untuk mengikutsertakan pihak dari akademisi atau pihak dari Pemerintah Pusat dalam penyusunan dokumen perencanaan sehingga akan menambah analisis yang baik dalam penyusunan dokumen perencanaan.

2. e-SAKIP yang dibuat oleh Pemerintah Kabupaten Gunungkidul belum bisa diterapkan karena masih banyaknya kekurangan pada sistem e-SAKIP tersebut. Belum adanya anggaran merupakan alasan Pemerintah Kabupaten 
Gunungkidul untuk tidak membuat sistem e-SAKIP melalui proses lelang atau melalui pihak ketiga. Pemerintah Kabupaten Gunungkidul tidak melaksanakan review IKU, akan tetapi Pemerintah Kabupaten Gunungkidul selalu melakukan perubahan IKU berdasarkan saran dan rekomendasi dari Kemen PAN \& RB melalui proses pendampingan yang dilaksanakan. Sedangkan pengukuran kinerja masih dilaksanakan dalam periode triwulanan karena sistem pengumpulan data kinerja yang ada pada Pemerintah Kabupaten Gunungkidul masih secara manual dengan mengirim surat kepada SKPD-SKPD untuk meminta data kinerja untuk keperluan pengukuran kinerja. Belum diterapkannya e-SAKIP juga merupakan alasan kenapa Pemerintah Kabupaten Gunungkidul melakukan pengukuran kinerja secara tahunan.

3. Pemerintah Kabupaten Gunungkidul khususnya pada Sekretariat Daerah Kabupaten Gunungkidul yang merupakan penanggungjawab dalam penerapan SAKIP sudah berusaha untuk peningkatan anggaran SAKIP. Akan tetapi, anggaran SAKIP yang ditetapkan dalam APBD masih belum cukup untuk pelaksanaan penerapan SAKIP pada Pemerintah Kabupaten Gunungkidul. Dengan anggaran sebesar Rp. 38.130.000, Pemerintah Kabupaten Gunungkidul menggunakan anggaran tersebut untuk penyusunan dokumen SAKIP, sosialisasi penyusunan dokumen SAKIP, bimbingan teknis, dan penyusunan e-SAKIP oleh pemberdayaan PNS Pemerintah Daerah. Sedangkan, hasil review LAKIP tidak dimasukkan dalam lampiran Dokumen LAKIP dikarenakan masalah waktu penyampaian LAKIP.

\section{KESIMPULAN}

Penelitian ini menganalisis perbedaan penerapan Sistem Akuntabilitas Kinerja Instansi Pemerintah (SAKIP) pada Pemerintah Daerah Kabupaten Gunungkidul dan Kota Yogyakarta. Berdasarkan pemaparan temuan dapat ditarik kesimpulan sebagai berikut:

1. Perencanaan Kinerja pada Pemerintah Kabupaten Gunungkidul dalam hal ini yaitu indikator kinerja sasaran Pemerintah Kabupaten Gunungkidul masih berorientasi output. Akan tetapi, Pemerintah Kabupaten Gunungkidul yang sudah melakukan review RPJMD selama satu kali yang ditandai dengan adanya perubahan RPJMD Pemerintah Kabupaten Gunungkidul.

2. Pengukuran Kinerja pada Pemerintah Kabupaten Gunungkidul dalam hal ini yaitu IKU Pemerintah Kabupaten Gunungkidul masih memiliki banyak indikator yang berorientasi output dan belum memiliki sistem pengumpulan data kinerja yang terintegrasi atau masih secara manual. Selain itu, Pemerintah Kabupaten 
Gunungkidul yang tidak melaksanakan review IKU dan melaksanakan pengumpulan data kinerja secara tahunan.

3. Pelaporan Kinerja pada Pemerintah Kabupaten

Gunungkidul dalam hal ini yaitu anggaran penyusunan LAKIP, hasil review LAKIP dan isi LAKIP. Anggaran penyusunan LAKIP pada Pemerintah Daerah Kabupaten Gunungkidul yang kecil, membuat penyusunan LAKIP menjadi tidak maksimal. Anggaran penyusunan LAKIP pada Pemerintah Kabupaten Gunungkidul adalah sebesar Rp. 38.130.000,-. Selain itu, hasil review LAKIP Pemerintah Kabupaten Gunungkidul tidak dilampirkan pada LAKIP yang akan disampaikan kepada Presiden melalui Kemen PAN \& RB.

4. Proses Evaluasi Kinerja pada Pemerintah Daerah Kabupaten Gunungkidul sudah melakukan analisis terhadap faktor keberhasilan dan kegagalan dalam melaksanakan sasaran strategis.

5. Faktor-faktor yang mempengaruhi penerapan SAKIP pada Pemerintah Daerah Kabupaten Gunungkidul adalah kejelasan pedoman SAKIP, komitmen Pemerintah Daerah, dan bantuan pemerintah pusat. Adanya kendala terkait kurangnya pemahaman terhadap pedoman SAKIP, kemudian kurangnya komitmen Pemerintah Daerah yang ditandai dengan anggaran SAKIP yang kecil membuat penerapan SAKIP pada Pemerintah Daerah Kabupaten
Gunungkidul menjadi kurang maksimal.

\section{SARAN}

Berdasarkan kesimpulan di atas, rekomendasi untuk Pemerintah Daerah Kabupaten Gunungkidul adalah sebagai berikut:

1. Komitmen Pemerintah Daerah merupakan faktor utama dalam penerapan SAKIP. Pemerintah Daerah Kabupaten Gunungkidul dalam hal ini Pimpinan Daerah beserta seluruh unsur Pemerintah Daerah sebaiknya berkomitmen untuk perbaikan penerapan SAKIP. Komitmen tersebut dapat berupa peran langsung dari Pimpinan Daerah untuk selalu mengawasi penerapan SAKIP dan peningkatan anggaran penerapan SAKIP.

2. Melakukan review terhadap dokumen perencanaan kinerja, RPJMD maupun Rencana Strategi SKPD. Khususnya terkait indikator kinerja dan sasaran agar bisa dilakukan perbaikan. Selain itu Pemerintah Daerah sebaiknya melakukan review IKU agar bisa dilakukan perbaikan terhadap indikatorindikator yang masih berorientasi output.

3. Pemerintah Daerah Kabupaten Gunungkidul sebaiknya berupaya untuk mengikutsertakan pihak ketiga baik itu pihak dari akademisi maupun dari pemerintah pusat, untuk seluruh proses penerapan SAKIP. Sehingga akan berdampak pada analisis yang semakin mendalam terkait penyusunan dokumendokumen SAKIP serta dapat 
memaksimalkan penerapan SAKIP.

4. Pemerintah Daerah Kabupaten Gunungkidul sebaiknya melakukan Pengukuran Kinerja secara Triwulan karena hal tersebut dapat memudahkan dalam melakukan pengendalian dan pengawasan kinerja.

5. Pemerintah Daerah Kabupaten Gunungkidul sebaiknya menerapkan sistem e-LAKIP dengan bantuan pihak ketiga karena akan sangat berguna untuk proses Pengukuran Kinerja. Sistem e-LAKIP dapat digunakan untuk pengumpulan data kinerja yang cepat dan akurat.

6. Pemerintah Daerah Kabupaten Gunungkidul sebaiknya meningkatkan anggaran penyusunan LAKIP sehingga dapat membantu dalam proses Pelaporan Kinerja. Peningkatan Anggaran Penyusunan LAKIP tersebut dapat digunakan untuk mengadakan kegiatan pelatihan atau bimbingan teknis sebelum penyusunan dokumen SAKIP serta dapat digunakan untuk proses pendampingan oleh Kemen PAN \& RB.

7. Melakukan review LAKIP dan melampirkan hasil review tersebut di dalam dokumen LAKIP sebelum disampaikan kepada Presiden melalui Kementerian PAN \& RB.

\section{DAFTAR PUSTAKA}

Akbar, Rusdi. Robyn Pilcher, dan Brian Perrin. 2010. Performance Measurement in
Indonesia: The Case of Local Government.

Akbar, Rusdi. 2012. Institutional Isomorphism dalam Akuntabiltas Kinerja Sektor Publik di Indonesia. Ebnews Fakultas Ekonomika dan Bisnis Universitas Gadjah Mada Yogyakarta. Edisi 13 November 2012.

Cooper, Donald R, and Schindler, Pamela S. 2006. Metode Riset Bisnis. edisi sembilan.jilid dua. jakarta, PT Media Global Edukasi

Gaspersz, Vincent, Sistem Manajemen Kinerja

Terintegrasi Balanced Scorecard dengan Six Sigma Untuk Organisasi Bisnis dan Pemerintah, Gramedia, Jakarta, 2003

Hartono, Jogiyanto. 2010. Analisis \& Disain. Andi, Yogyakarta.

Indianto, Nur. dan Supomo, Bambang. 2002. Metodelogi Penelitian Bisnis Untuk Akuntansi dan Manajemen. Yogyakarta, BPFE.hal147.

JB Ghartey, Crisis. Accountability and Development in the Third World. London, 1987.

Kementerian Pendayagunaan Aparatur Negara, Modul Pelatihan Penyusunan Kinerja, 2005

Lembaga Administrasi Negara RI, Buku Pedoman Penyusunan Pelaporan Akuntabilitas Kinerja Instansi Pemerintah, 2003.

Lembaga Administrasi Negara dan Badan Pengawasan Keuangan dan Pembangunan, Modul Sosialisasi Sistem Akuntabilitas Kinerja Instansi 
Pemerintah (AKIP), Cetakan ketiga, 2001.

LV Carino, Accountability, Corruption and Democracy: A Clarification of Concepts, (in the Asian Review of Public Administration, Vol. III. No. 2, December 1991)

Mahmudi. 2010. Manajemen Kinerja Sektor Publik, UPP STIM YKPN, Yogyakarta.

Marzuki. 2006. Metodelogi Riset. Yogyakarta:BPFE UII

Miles, M.B., dan A.M. Huberman. 1992, Analisa Data Kualitatif, UI Press Jakarta

Moleong, L.J. 2006. Metode Penelitian Kualitatif. Bandung: Remaja Rosdakarya.

Muthoharoh, Ika. 2009. Peran Pajak Parkir dalam Menunjang Pendapatan Asli Daerah (PAD), Jurnal pascasarjana UIN, Malang.

Pusdiklatwas, BPKP. 2007. Akuntabilitas Instansi Pemerintah, Edisi kelima.

Rasul, Sjahruddin. 2003. Pengintegrasian Sistem Akuntabilitas Kinerja dan Anggaran Dalam Perspektif UU No. 17 Tahun 2003 Tentang Keuangan Negara, Perum Percetakan Negara Indonesia, Jakarta.

Paul, Samuel. 1992. Accountability in Public Service: Exit, Voice and Control, (The World Development Journal, Vol.20, No.7)

Sugiyono, 2001, Statistika untuk Penelitian, Bandung: Alfabeta.
Supartini, Nunik. 2012. Evaluasi Implementasi Sistem Akuntabilitas Kinerja Instansi Pemerintah (SAKIP), Studi Kasus Pada Pemerintah Kabupaten Kotawaringin Barat. Tesis. Universitas Gadjah Mada, Yogyakarta. Tidak dipublikasikan.

-------, Instruksi Presiden RI Nomor 7 Tahun 1999 Tentang Akuntabilitas Kinerja Instansi Pemerintah

-------, Keputusan Kepala Lembaga Administrasi Negara Nomor:239/IX/6/8/2003

Tentang Perbaikan Pedoman Penyusunan Pelaporan Akuntabilitas Kinerja Instansi Pemerintah

-------, Peraturan Menteri Dalam Negeri Nomor 34 Tahun 2011 Tentang Pedoman Evaluasi Laporan Akuntabilitas Kinerja Instansi Pemerintah Di Lingkungan Kementerian Dalam Negeri

-------, Peraturan Menteri Negara Pendayagunaan Aparatur Negara dan Reformasi Birokrasi Nomor 29 Tahun 2010 Tentang Pedoman Penyusunan Penetapan Kinerja dan Pelaporan Akuntabilitas Kinerja Instansi Pemerintah

------, Peraturan Menteri Negara Pendayagunaan Aparatur Negara dan Reformasi Birokrasi Nomor 25 Tahun 2012 Tentang Petunjuk Pelaksanaan Evaluasi Akuntabilitas Kinerja Instansi Pemerintah

-------, Peraturan Menteri Negara Pendayagunaan Aparatur 
Negara dan Reformasi

Birokrasi Nomor 20 Tahun

2013 Tentang Perubahan Lampiran Peraturan Menteri

Negara Pendayagunaan

Aparatur Negara dan

Reformasi Birokrasi Nomor 25 Tahun 2012 Tentang

Petunjuk Pelaksanaan

Evaluasi Akuntabilitas

Kinerja Instansi Pemerintah

-------, Peraturan Menteri Negara

Pendayagunaan Aparatur

Negara dan Reformasi

Birokrasi Nomor 53 Tahun

2014 Tentang Petunjuk

Teknis Perjanjian Kinerja,

Pelaporan Kinerja dan Tata

Cara Reviu Atas Laporan Kinerja Instansi Pemerintah

, Peraturan Presiden Republik

Indonesia Nomor 29 Tahun

2014 Tentang Sistem

Akuntabilitas Kinerja Instansi

Pemerintah

------, Peraturan Bupati

Gunungkidul Nomor 17

Tahun $2007 \quad$ Tentang

Pedoman Pelaksanaan Sistem

Akuntabilitas Kinerja Instansi

Pemerintah (SAKIP) di

Lingkungan Pemerintah

Kabupaten Gunungkidul 
